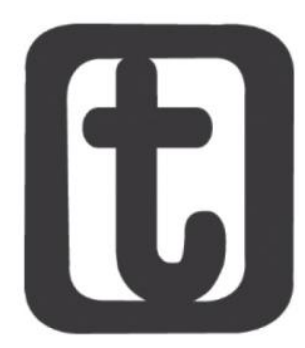

\title{
PENAS ALTERNATIVAS: (IN) UTILIDADE DO TRABALHO PARA PRESTAÇÃO DE SERVIÇOS À COMUNIDADE
}

\author{
Alternative features: (in) usefulness of community service work \\ José Edson Martins* \\ https://orcid.org/0000-0001-5584-2529
}

\section{RESUMO}

O código penal brasileiro vigente adotou a teoria mista da pena, que combina a função penal de retribuição, prevenção geral e especial, como justificativa e finalidade da pena. Diante disso, neste estudo teórico de revisão bibliográfica investiga-se a (in) utilidade do trabalho para a finalidade da pena alternativa de prestação de serviços à comunidade. Empregou-se, nesse sentido, o trabalho como "chave de leitura" e categoria analítica para estudar as possibilidades e limites da aplicação do trabalho comunitário como instrumento de retribuição penal e prevenção da prática delituosa. O trabalho comunitário condiciona a forma jurídica e social dessa pena alternativa, contudo concluiu-se que a sua utilização, como instrumento penal, não produz os efeitos esperados.

\section{PALAVRAS-CHAVES}

Prestação de serviços à comunidade. Pena alternativa. Trabalho. Finalidade das penas.

\section{ABSTRACT}

The current Brazilian penal code adopted the mixed theory of punishment, which combines the criminal function of retribution, general and special prevention, as justification and purpose of the penalty. Therefore, this theoretical study of bibliographic review investigates the (in) usefulness of the work for the purpose of the alternative penalty of community service. In this sense, work was used as a "reading key" and analytical category to study the possibilities and limits of the application of community work conditions the legal and social form of this alternative penalty, but it has been concluded that its use as a criminal instrument does not produce the expected effects.

\section{KEYWORDS}

Provision of services to the community. Alternative penalty. Job. Purpose of penalties.

* Assistente Social. Especialista em Segurança Pública e Especialista em Direitos Humanos e Ressocialização. Assistente Social da Unidade Prisional de Abaeté Minas Gerais. R. Treze de Maio, 1118, Santo Antônio, Abaeté (MG), CEP.: 35620-000. E-mail: joseedsonm@hotmail.com.

DOI 10.22422/temporalis.2020v2on40p233-249 Commons Atribuição 4.0 Internacional (https://creativecommons.org/licenses/by/4.0/deed.pt BR), que permite copiar e redistribuir o material em qualquer suporte ou formato, bem como adaptar, transformar e criar a partir deste material para qualquer fim, mesmo que comercial. O licenciante não pode revogar estes direitos desde que você respeite os termos da licença. 


\section{temporolis \\ MARTINS, JOSÉ EDSON}

\section{INTRODUÇÃO}

$\mathrm{N}$ este estudo ${ }^{1}$ investiga-se a (in) utilidade do trabalho para a finalidade da pena alternativa de prestação de serviços à comunidade (PSC). Na sua origem o Código Penal de 1940 (BRASIL, 1940), vigente até hoje no Brasil, não previa as penas restritivas de direitos, conhecidas como penas alternativas, trazendo em seu âmago a pena de privação de liberdade. Em 1984, em decorrência aos problemas advindos do cárcere, a reforma da parte geral do Código Penal (lei 7.209/84) (BRASIL, 1984) estabeleceu as penas alternativas de prestação de serviços à comunidade, interdição temporária de direitos e limitação de fim de semana ampliadas, posteriormente, pela lei 9.714/98 (BRASIL, 1998) que acrescentou a prestação pecuniária e a perda de bens e valores as penas alternativas.

No entanto, "[...] até o ano de 2000 pouco se tinha avançado na estruturação da execução desse tipo de sanção [...]" (BARRETO, 2010, p. 11) alternativa. A partir do ano de 2000, com a criação da Central Nacional de Apoio e Acompanhamento às Penas e Medidas Alternativas (CENAPA) as Centrais de Penas e Medidas Alternativas (CPMA), responsáveis pela execução, fiscalização e monitoramento das penas alternativas, expandiram-se (BARRETO, 2010, p. 17) para todo o país. Essas centrais constituem-se um novo campo de atuação do Serviço Social ${ }^{2}$ no qual o monitoramento e acompanhamento do cumprimento dessas penas alternativas vem sendo realizado por equipes interdisciplinares formadas, principalmente, por psicólogos e assistentes sociais.

Entre as sanções alternativas executadas e acompanhadas pela CPMA, a prestação de serviços à comunidade vem se destacando por ser a mais aplicada nas capitais brasileiras (ILANUD BRASIL, 2006, p. 258) e considerada a "[...] mais extraordinária pena alternativa, que teve e tem a maior repercussão e melhor aceitação mundialmente, desde a pioneira experiência inglesa de 1972" (BITENCOURT, 2000, p. 89). Porém, "[...] a realidade das penas e medidas alternativas ainda é pouco conhecida no Brasil, sendo raros os estudos nessa área. As pesquisas desenvolvidas até o momento são análises mais gerais [...]" (JUNQUEIRA, 2010, p. 13-14) o que contribui mais para defesa desse dispositivo penal do que para a análise crítica de sua eficácia.

Neste estudo, ao contrário disso, buscou-se desenvolver análises mais especificas capazes de captarem as singularidades da pena alternativa de PSC para desenvolver uma análise crítica da sua eficácia a partir dessas especificidades. A categoria trabalho, singular a PSC, a distingue das outras penas alternativas, no entanto os estudos realizados, até hoje, sobre a temática da PSC abordam a categoria trabalho de forma marginal e geral sem utilizar essa "chave de leitura" 3 para explicar o funcionamento dessa pena, suas

\footnotetext{
${ }^{1}$ Este estudo é uma adaptação do artigo científico realizado, em 2019, para conclusão do curso de pósgraduação lato sensu em Segurança Pública.

${ }^{2}$ Por ser um novo espaço ocupacional do Serviço social não há muitos estudos sobre o tema na área do Serviço Social. Em última pesquisa, no dia 04/07/2020, ao banco de dados do Google Acadêmico utilizando como palavras chaves Serviço Social e penas alternativas (no título) encontrei somente sete (07) resultados e somente um (01) artigo científico entre esses.

${ }^{3}$ Nas sociedades capitalistas o trabalho continua sendo central para os indivíduos e a coletividade como elemento organizador da vida social e categoria analítica, embora Offe (1989) tenha anunciado a perda da centralidade do trabalho nessas sociedades.
}

Temporalis, Brasília (DF), ano 20, n. 40, p. 233-249, jul./dez. 2020. | ISSN 2238-1856 


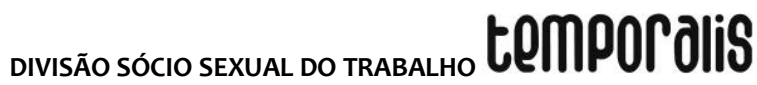

potencialidades e limites. Em contraste a isso, utilizou-se aqui o trabalho como "chave de leitura" e categoria analítica para pensar a finalidade da pena de PSC, o "por que punir " como diria Bicudo (2010).

No Brasil, o "por que punir" práticas delituosas tem como finalidade e justificativa a reprovação e prevenção de crimes (art. 59, CP). O trabalho, dentro dessa concepção, na pena alternativa de PSC necessita, inevitavelmente, ser concebido como instrumento de reprovação e prevenção de futuros crimes, logo é imprescindível questionarmos qual a (in) utilidade do trabalho para a finalidade da pena de PSC. Seria possível o trabalho provocar um "mal justo" capaz de retribuir o "mal injusto" causado pelo crime? O trabalho seria um mecanismo de validação da lei e intimidação penal apropriado para evitar futuros delitos? É possível o trabalho ser um instrumento de neutralização e "(re) socialização" adequado para prevenção da reincidência?

Esta pesquisa de revisão bibliográfica (GIL, 2008, p. 50-51), para além da lacuna ${ }^{4}$ existente na literatura especializada, faz-se necessário para compreensão crítica das possibilidades e limites da utilização do trabalho como instrumento de sanção penal. E, também, poderá contribuir para os assistentes sociais e psicólogos apropriarem-se de conhecimentos teóricos uteis para atuação profissional nas Centrais de Penas e Medidas Alternativas.

\section{O TRABALHO COMO SANÇÃO PENAL}

Nas sociedades capitalistas, a tipificação de crimes e penas no direito penal são expressões das relações sociais vigentes que, por sua vez, são expressões, em última instância, do modo de produção capitalista, visto que "[...] o modo de produção da vida material condiciona o processo da vida social, política e intelectual” (MARX, 2008a, p. 47). Condiciona, mas não determina, por isso Engels (apud HARNECKER,1971) observa que:

O desenvolvimento político, jurídico, filosófico, religioso, literário, artístico etc, descansa no desenvolvimento econômico. Mas, todos eles também repercutem uns sobre os outros e sobre a base da necessidade econômica que se impõe sempre, em última instância (ENGELS apud HARNECKER, 1971, p. 96).

A base da necessidade econômica, desta forma, se impõe em última instância, ao direito penal e a pena, por sua vez, se impõe como "ultima ratio" aos homens como necessária para fins de regulação da convivência social, apesar de "[...] toda punição constitui um ato pernicioso; toda punição constitui, em si mesma, um mal” (BENTHAM, 1974 apud BICUDO, 2010, p. 89). A pena aplicada aos indivíduos, que violam as leis tipificadas como crimes, assume diversas formas ao longo do tempo, dentre elas o trabalho. A utilização

\footnotetext{
${ }^{4}$ Em última consulta ao banco de dados Google Acadêmico em 04/05/2020 utilizando como critério de inclusão/exclusão: a) trabalhos acadêmicos produzidos entre 1984 a 2020; b) "prestação de serviços à comunidade" como palavra-chave; c) a palavra-chave deveria aparecer no título do trabalho. Localizei setenta e quatro (74) documentos sendo excluídos os documentos que tratavam da medida socioeducativa de prestação de serviços à comunidade aplicada a adolescentes infratores. Desses documentos extraiu-se somente os artigos científicos e dissertações de mestrado, totalizando sete (07) documentos, que, juntamente com outros livros da literatura especializada, formam a base a partir do qual analisou-se a (in) utilidade do trabalho para a função de reprovação e prevenção busca pela pena de PSC.
}

Temporalis, Brasília (DF), ano 20, n. 40, p. 233-249, jul./dez. 2020. | ISSN 2238-1856 


\section{temporalis marrus, Oose Eson}

do trabalho, como instrumento de sanção penal, não é novidade na história da humanidade.

Durante vários séculos a pena de trabalho forçado, conhecida como pena de galés, esteve presente em diversas legislações de diferentes países. Até o século XIX, no Brasil ainda existia essa pena cruel e infamante na qual o condenado, cuja força de trabalho era utilizada em trabalhos públicos, eram obrigados a "[...] andarem com calceta no pé, e corrente de ferro, juntos ou separados [...]" (art. 44, Código Criminal de 1830) (BRASIL, 1830) sofrendo, muitas vezes, humilhação pública e maus tratos. Em 1890, a pena de galés é abolida, no entanto a instrumentalização do trabalho para fins penais não desapareceu completamente do direito penal brasileiro. No Código Penal de 1940, o trabalho torna-se, inicialmente, complemento das penas privativas de liberdade e das medidas de segurança e detentivas não tendo, todavia, status de pena. Contudo, em 1984, a reforma da parte geral do Código Penal instituiu, pela primeira vez na legislação brasileira, a pena alternativa de prestação de serviços à comunidade que devolveu ao "trabalho" o status de pena, embora continue sendo empregado no sistema prisional como complemento penal para fins de "(re) socialização".

A pena alternativa de prestação de serviços à comunidade ou a entidades públicas constitui-se na atribuição de tarefas gratuitas ao condenado a pena superior a seis meses de privação de liberdade observado o art. 44 do Código Penal Brasileiro. Essas sanções, entre elas a PSC, são autônomas e substitui as penas privativas de liberdade quando presente certos requisitos legais: a) pena aplicada não for superior a quatro anos de privação de liberdade; b) crime praticado sem violência ou grave ameaça à pessoa; c) réu não reincidente em crime doloso; d) qualquer pena se o crime for culposo; e) prognostico de substituição favorável (art. 44, CP). Em caso de descumprimento da PSC a sanção "[...] converte-se em [pena] privativa de liberdade" ( $\$ 4^{\circ}$, art. 44, CP).

As tarefas serão desempenhadas em entidades públicas e instituições ou programas sem fins lucrativos tais como: entidades assistenciais, hospitais, escolas e outros estabelecimentos congêneres, bem como em programas comunitários e estatais. 0 trabalho levará em consideração as aptidões do condenado e será executado na proporção de uma hora de trabalho por dia de condenação de forma a não prejudicar sua jornada normal de trabalho e alterar o mínimo possível sua vida social (art. 46, CP). Daqui em diante, designaremos tal tarefa como trabalho comunitário para distingui-la do trabalho assalariado e de outras formas de trabalho, como o informal.

Nessas instituições ${ }^{5}$, o condenado a pena de PSC insere-se como força de trabalho gratuita e executa o trabalho comunitário de manutenção predial, limpeza, serviços administrativos, serviços gerais e outros necessários para prestação de serviços de saúde, educação, assistência social, etc. Assim, o condenado, por força da lei e manutenção da sua liberdade, presta um serviço à comunidade indiretamente por mediação da instituição. A força de trabalho ao ser consumida minimiza a falta de mão de obra das instituições (OLIVEIRA, 2011), bem como realiza trabalhos, como por exemplo reformas

\footnotetext{
5 Em Porto Alegre/RS 75,4 \% dos condenados à PSC comparecem à entidade para o cumprimento; Curitiba/PR 31,2\%; fortaleza/CE 70\%; Campo Grande/MS 73,4\%; BH/MG 58,5\%; Recife 72\% e São Paulo/SP 40\% (ILANUD BRASIL, 2006). Ou seja, uma grande parte dos condenados não iniciam o cumprimento da pena.
}

Temporalis, Brasília (DF), ano 20, n. 40, p. 233-249, jul./dez. 2020. | ISSN 2238-1856 


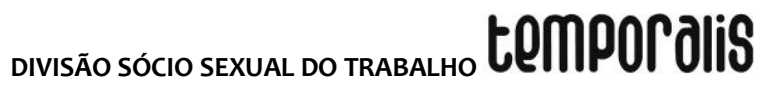

de móveis, que, muitas das vezes, não seriam feitos por falta de recursos financeiros. Chamaremos, daqui em diante, de trabalhador comunitário o indivíduo julgado e condenada ao cumprindo da pena alternativa de PSC.

O trabalho comunitário ocupa lugar central nessa pena alternativa na medida em que, não só a distingue das outras penas alternativas, mas também condiciona sua forma jurídica, política e social $\left(M_{\text {ARTINS }}{ }^{2}, 2016\right.$, p. 101). Os limites e as possibilidades desta pena são construídos e dados, majoritariamente, pelo trabalho comunitário que é, digamos, o centro de gravidade da pena de PSC. Além disso, constitui-se no ponto de interseção entre o campo jurídico, econômico e social, já que "[...] o fato desse trabalho se metamorfosear em determinação judicial não anula nem nega o fato desse trabalho se efetivar em uma sociedade organizada a partir do modo de produção capitalista" (MARTINS, 2016, p. 92).

É inevitável, dentro dessa concepção, a instrumentalização do trabalho comunitário para os fins penais propostos pela PSC. Mas, afinal qual seria a finalidade da pena de PSC? Nossa legislação ao prever que a sanção penal deve ser " [...] suficiente para reprovação e prevenção do crime" (art.59, CP) adotou a teoria mista ou unificadora como justificativa e finalidade da pena. Nesse sentido, Hassemer (apud SANTOS,2008) coloca que:

\begin{abstract}
As modernas teorias unificadas da pena criminal representam uma combinação das teorias isoladas, realizadas com o objetivo de superar as deficiências individuais de cada teoria [...]. Assim, a pena representaria (a) retribuição do injusto realizado, mediante compensação ou expiação da culpabilidade, (b) prevenção especial positiva mediante correção do autor pela ação pedagógica da execução penal, além de prevenção especial negativa como segurança social pela neutralização do autor e, finalmente (c) prevenção geral negativa através da intimidação de criminosos potenciais pela ameaça penal e prevenção geral positiva como manutenção/reforço da confiança na ordem jurídica etc. (HASSEMER, 2000, p. 34 apud SANTOS, 2008, p. 469-470).
\end{abstract}

Essas funções atribuídas à pena de PSC dentro da política criminal oficial possuem como fim último o controle do crime e da criminalidade. Mas, para a Criminologia Critica tais funções declaradas ou aparentes propagadas pelo discurso oficial encobrem as funções reais ou latentes da pena ligadas a dominação e controle social das classes subalternas. Nessa pesquisa, entretanto, estudamos somente a relação entre o trabalho comunitário e as funções declaradas da pena. A seguir analisa-se os limites e possibilidades da utilidade do trabalho comunitário para a finalidade da pena alternativa de PSC.

\section{O TRABALHO COMUNITÁRIO COMO RETRIBUIÇÃO PENAL}

Independente da época ou lugar o homem relacionar-se com a natureza, pela mediação do trabalho, para (re) produzir as condições materiais necessárias a existência humana, uma vez que o homem sobrevive da natureza com a " [...] qual ele tem de ficar num

\footnotetext{
${ }^{6}$ Martins (2016) estudou a centralidade do trabalho na PSC das medidas socioeducativas (MSE) aplicadas a adolescentes em conflito com a lei, mas pela semelha entre as sanções aquilo que vale para PSC/MSC, também, vale, em parte, para a pena de PSC.
}

Temporalis, Brasília (DF), ano 20, n. 40, p. 233-249, jul./dez. 2020. | ISSN 2238-1856 


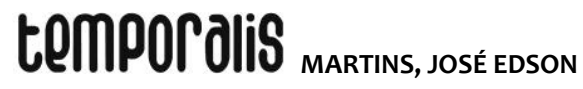

processo contínua para não morre" (MARX, 2008b, p. 84). O homem faz da natureza a extensão do seu próprio corpo, na medida em que é seu meio de vida imediato, o instrumento e a matéria da sua atividade vital. "No modo (Art) da atividade vital encontra-se o caráter inteiro de uma espécie, seu caráter genérico, e a atividade consciente livre é o caráter genérico do homem" (MARX, 2008b, p. 84).

O animal, assim como o homem, "[...] é imediatamente um com a sua atividade vital. Não se distingue dela. É ela” (MARX, 2008b, p. 84). Então como poderia o homem ser castigado e punido com algo que é sua condição humana? Se não é possível infligir sofrimento a um peixe fazendo-o nadar, então não seria possível também, do ponto de vista da natureza, causar sofrimento ao homem fazendo-o trabalhar.

Para o cristianismo, no entanto, o homem ao pecar por comer o fruto da árvore proibida teria sido punido por Deus: "Com o suor do teu rosto comerás o teu pão, até que voltes ao solo [...]" (GÊNESES 3:19)7. Se o trabalho, desta forma, é uma maldição e punição divina a humanidade, o trabalho comunitário seria uma espécie de castigo dentro do próprio castigo. Seria, por isso, inconcebível, dentro dessa concepção religiosa, o trabalho comunitário ser instrumento de retribuição penal e expiação do "mal" causado pelo delito, visto que o trabalho já castiga, pune e expia o "mal" do "pecado original", diariamente, até o fim da existência do homem.

Adam Smith, segundo Marx (2011), concebia o trabalho dessa forma: como "maldição", enquanto " [...] o 'repouso' aparece como o estado adequado, sinônimo de 'liberdade' e 'felicidade' " (MARX, 2011, p. 816). Acusa Smith de não reconhecer que o indivíduo "[...] 'em seu estado normal de saúde, força, atividade, habilidade, agilidade' também tem a necessidade de uma porção normal de trabalho e de suspensão do repouso" (MARX, 2011, p. 817). Por esse motivo, ao contrário de Smith, Marx concebe o trabalho como "[...] atividade positiva, criadora [...]" (MARX, 2011., p. 821), portanto “[...] autorrealização, objetivação do sujeito, daí liberdade real [...]” (MARX, 2011, p. 817). Entretanto, concorda com Smith que o trabalho "[...] em suas formas históricas como trabalho escravo, servil e assalariado, sempre aparece como repulsivo, sempre como trabalho forçado externo, perante o qual o não trabalho aparece como 'liberdade' e 'felicidade"' (MARX, 2011, p. 817).

Nas sociedades capitalistas, a forma histórica assalariada hegemônica, além de repulsivo, leva inevitavelmente o homem a estranhar sua própria atividade vital que lhe defronta hostil e estranha, já que nesse sistema de produção "[...] a atividade do trabalhador não é a sua auto-atividade. Ela pertence a outro, é a perda de si mesmo" (MARX, 2008b, p. 83). Logo,

O trabalho externo, o trabalho no qual o homem se exterioriza é um trabalho de auto sacrifício, de mortificação. Finalmente, a externalidade (Ausserlchkeit) do trabalho aparece para o trabalhador como se [o trabalho] não fosse seu próprio, mas de um outro, como se [o trabalho] não lhe pertencesse, como se ele no trabalho não pertencesse a si mesmo, mas a um outro (MARX, 2008b, p.83)

\footnotetext{
${ }^{7}$ Ver BÍBLIA King James.
} 


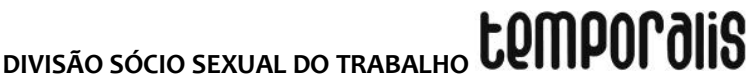

Isso leva o trabalho em troca de um salário, em condições consideradas "normais", a gerar angústia e sofrimento no trabalhador. E, portanto, nas sociedades capitalistas o trabalho comunitário não poderia causar um sofrimento ainda maior ao trabalhador comunitário, tendo em vista que o trabalhador "livre" já sofre desse "mal", dessa "maldição", dessa "mortificação" cotidianamente. Na "economia do sofrimento" seria mais "do mesmo" ou até menos, já que a carga horária diária do trabalhador comunitário, geralmente, é menor que a carga horária normal do trabalhador assalariado. Consequentemente, o trabalho comunitário, em termos gerais, não produz os efeitos esperados pela retribuição ${ }^{8}$ da pena por não conseguir expiar o mal ou compensar a culpabilidade pela "[...] imposição de um mal justo contra o mal injusto do crime, necessário para realizar a justiça ou restabelecer o Direito [...]” (SANTOS, 2008, p. 461).

Ora, nem todos que cumpre a pena de PSC necessitam vender sua força de trabalho no mercado para sobreviver. Aos olhos desses, o trabalho comunitário seria sofrimento e mortificação em comparação a sua vida de repouso e ócio na qual goza de liberdade e felicidade. Logo a retribuição aconteceria no ato de trabalhar não se separando dele. Semelhante efeito e resultado, provavelmente, não sofreria perda se o trabalho comunitário fosse remunerado, contudo se fosse um trabalhador típico e remunerasse sua atividade a pena não seria um castigo, mas um prêmio, até mesmo uma recompensa pelo crime.

$\mathrm{Na}$ prestação de serviços à comunidade "[...] os serviços devem ser prestados gratuitamente, pois do contrário não seriam penas, mas sim um emprego [...]" (SHECARIA, 1993, p. 14). A natureza gratuita do trabalho comunitário é, ao mesmo tempo, a negação do emprego e a afirmação da pena. Somos levados, por isso, a penar que, no geral, a função de retribuição da pena na PSC encontra-se mais na negação da remuneração do que no ato de trabalhar. Nesse sentido, "[...] a gratuidade constitui ônus para o condenado, assumindo aí o seu caráter retributivo ou expiatório, dando à pena um conteúdo aflitivo, sem o qual a prestação de serviços à comunidade não seria uma pena propriamente dita" (FELIPETO, 1994, p. 6).

\section{O TRABALHO COMUNITÁRIO COMO PREVENÇÃO GERAL DA PENA}

No final do século XX, a prevenção geral ganhou uma concepção positiva pós-moderna (SANTOS, 2008, p. 468). Dentro dessa visão, "para Jakobs [, um dos grandes pensadores da prevenção geral positiva, ] a norma penal constitui uma necessidade funcional sistêmica de estabilização das expectativas sociais por intermédio da aplicação da pena ante a frustração que decorre da violação da norma" (CACICEDO, 2014, p. 42). A violação da norma, considerado o agente potencial de perturbação social, provoca uma reação social expressa na pena que "[...] protege as condições para as interações interpessoais e tem função preventiva na medida em que assegura a validade da norma, tida como o

\footnotetext{
8 "As concepções absolutas têm origem no idealismo alemão, sobretudo com a teoria da retribuição ética ou moral de Kant a aplicação da pena decorre de uma necessidade ética, de uma exigência absoluta de justiça, sendo eventuais efeitos preventivos alheios à sua essência” (PRADO, 2004, p. 2).
}

Temporalis, Brasília (DF), ano 20, n. 40, p. 233-249, jul./dez. 2020. | ISSN 2238-1856 


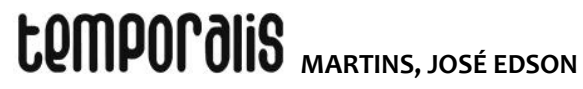

próprio bem jurídico-penal, e restabelece a confiança para a estabilidade e integração do sistema social" (CACICEDO, 2014, p. 42).

A simples aplicação de qualquer pena "[...] realiza a função de afirmar a validade da norma penal violada [...]" (SANTOS, 2008, p. 469), por isso é inconcebível uma escala de validação na qual determinada pena afirma a validade da norma mais do que outra. Dizer "[...] que uma norma que prescreve uma certa conduta vale, significa que uma tal norma existe [...]" (KELSON apud LIMA, 1993, p. 91) em determinado tempo e espaço. Nessa compreensão, o trabalho comunitário, enquanto instrumento de sanção penal e reação social a perturbação da expectativa social expressa na lei, afirma a validade da norma jurídica violada e comunicada simbolicamente a população que aquela norma, mesmo violada, continua produzindo os seus efeitos e, por conseguinte, corrobora para prevenção geral positiva.

Ao reafirmar a validade da norma violada a sanção penal reforça a confiança na norma jurídica, mas, ao contrário da validação, há penas que fortalecem a confiança mais do que outras. O fortalecimento da confiança na norma jurídica está na razão direta da aplicação da lei e da percepção da proporcionalidade entre o crime e a pena. A proporcionalidade pode ser expressa na máxima: "[...] para que o castigo produza o efeito que dele se deve esperar, basta que o mal que causou ultrapasse o bem que o culpado retirou do crime" (BECCARIA, 2010, p. 63).

Quando a pena não é aplica ou não causa um "mal justo" proporcional, que ultrapasse as vantagens do crime, provoca, geralmente, na população sensação de impunidade. Segundo o Relatório Índice de Confiança na Justiça no Brasil (ICJBrasil), $3^{\circ}$ bimestre/2011, para $66 \%$ dos entrevistados "[...] há existência de penas alternativas é um fator que contribui para o aumento da impunidade" (Ibid., p. 20). A população "[...] ainda não vê com bons olhos [as penas alternativas]. Eles acham que o fato do condenado estar apenas prestando um serviço [comunitário] ao invés de estar preso não faz ele 'pagar' pelo crime que cometeu" (ENTREVISTADO A apud OLIVEIRA, 2011, p. 55). O trabalho comunitário, como podemos perceber, reafirma a validade da lei, mas não fortalece a confiança nas leis, na medida em que gera sensação de impunidade na maioria da população que, por sua vez, contribuiu para perda de confiança na própria lei e no Poder Judiciário.

Essa sensação de impunidade produz, também, na população a sensação social e a "ideia" de que o crime "compensa" por ser vantajoso o que, por sua vez, colabora diretamente para redução dos efeitos da prevenção geral negativa. Na teoria da prevenção geral negativa o fim político das penas é “[...] o terror que imprimem nos corações inclinados ao crime [...]" (BECCARIA, 2010, p. 47) intimidando-os a não delinquir. Bentham (2002, p. 27), nessa direção, afirma que há nas penas um valor verdadeiro e outro aparente. O valor verdadeiro é o "mal real" experimentado pelo condenado durante a execução da pena enquanto o valor aparente é o "mal provável" experimentado pela imaginação dos homens quando presenciam a execução da pena ou simplesmente se descreve as penas nas leis. 


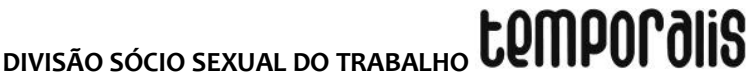

O “mal provável”, se fizer isso lhe acontecerá esse isso, enunciado pela pena, por meio da ameaça penal e coação psicológica", produz nos indivíduos efeitos simbólicos e psicológicos intimidatórios que levam os indivíduos a deixarem de "[...] praticar atos ilícitos em razão do temor de sofrer a aplicação de uma sanção penal” (PRADO, 2004, p. 3). Deste modo, toda pena pelo simples fato de ser uma sanção penal provoca tais efeitos simbólicos na população prevenindo futuros crimes, mas a intensidade pode variar de uma pena para outro, assim como de uma pessoa para outra ${ }^{10}$. O trabalho comunitário, "mal provável", teria algum potencial para intimidar aqueles inclinados ao crime? Há indícios que sugerem resultados inexpressivos e baixa intensidade de tais efeitos como veremos.

Dos brasileiros que trabalham na indústria manufatureira $62 \%$ temem, no prazo de dez anos, perder os empregos para os robôs. É o que revela a pesquisa do Banco Interamericano de Desenvolvimento (BID) e da Organização Latinobarómetro divulgada em 2018. Segundo o Indicador de Confiança do Consumidor da Confederação Nacional de Dirigentes Lojistas (CNDL) e do Serviço de Proteção ao Crédito (SPC Brasil, 2018), publicado em 2018, 29\% dos trabalhadores têm medo alto ou médio de perder o emprego, ou seja, um em cada três brasileiros temem serem demitidos. Nesse cenário e considerando a necessidade de sobrevivência do trabalhador típico, mesmo que o trabalho seja fonte de sofrimento e angústia nas sociedades capitalistas, é legítimo reconhecer que o trabalho tem sido percebido mais como benefício do que como castigo e punição a ser evitado. O medo nasce do "mal provável" de não ter trabalho para sobreviver e sustentar sua família e não do "mal provável" de ter que trabalhar. Portanto, a intimidação penal, via trabalho comunitário, ao inverter essa lógica vivida pelos trabalhadores no seu cotidiano só pode produz efeitos simbólicos intimatórios insignificantes sob os trabalhadores, mas talvez seja um pouco maior para os não trabalhadores.

Essa intimidação e ameaça penal torna-se real na vida social pelo exemplo dado e vivenciado pelo trabalhador comunitário durante a execução da pena de PSC. "O castigo que o réu padece é um painel em que todo o homem pode ver o retrato do que lhe teria acontecido, se infelizmente incorresse no mesmo crime" (BENTHAM, 2002, p. 25). Contudo, segundo estimativa da Pesquisa Nacional por Amostra de Domicílios (PNAD) Contínua, trimestre encerrado em março de 2020, o Brasil possui uma população de 85,9 milhões de brasileiros ocupados trabalhando no setor formal ou informal que vivem cotidianamente o "mal real" análogo ao trabalhador comunitário. A capacidade do trabalho comunitário de amedrontar e intimidar tais trabalhadores a ponto de convencêlos a desistirem de cometer determinado crime seria ínfima porque o "mal provável"

\footnotetext{
9“É a denominada prevenção geral intimidatória, que teve clara formulação em Feuerbach (teoria da coação psicológica), segundo a qual a pena previne a prática de delitos porque intimida ou coage psicologicamente seus destinatários" (PRADO, 2004, p. 3).

${ }^{10}$ Os efeitos da prevenção geral negativa, isto é, "[...] ocorre de fato nos indivíduos que estatisticamente teriam poucos estímulos para delinqüir, são os popularmente chamados 'homens de bem' que teme a norma e a aplicação da sanção pena" (FELIPETO, 1994, p. 2).
}

Temporalis, Brasília (DF), ano 20, n. 40, p. 233-249, jul./dez. 2020. | ISSN 2238-1856 


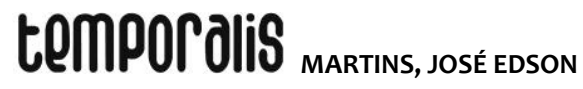

utilizado para ameaçar e coagir é semelhante ao "mal real" vivido pelos trabalhadores que são "condenados" ao trabalho sem julgamento.

Muitos trabalhadores até desejam sofrer desse "mal", ter um emprego. No entanto, conforme a pesquisa supracitada a taxa de desocupado no país é de 12,9\% o que coloca 12,7 milhões de brasileiros à procura de emprego. Outros 30 milhões possuem sua força de trabalho subutilizada, enquanto 5,4 milhões de trabalhadores desalentados desistiram de procurar emprego (BENTHAM, 2002), embora desejem trabalhar. Diante disso, a instrumentalização do trabalho comunitário para fins de intimidação penal dificilmente poderia produzir grandes efeitos simbólicos ou psicológicos inibitórios nos trabalhadores desocupados, "subutilizados" ou desalentados, uma vez que o trabalho, nesse contexto, simboliza muito mais o fim da insegurança e angústia causa pela falta de trabalho do que um castigo e sofrimento que se deve evitar a qualquer custo.

Como vimos, o trabalho comunitário não tem força necessária para intimidar aqueles inclinados ao crime, mas talvez a intimidação pudesse ser provocada pelo seu caráter "comunitário", ou seja, pela natureza gratuita do trabalho. Parece pouco provável que o trabalho não remunerado seja rejeitado ao ponto de desestimular os indivíduos de violar as leis, na medida em que de acordo com PNAD Contínua (apud BÔAS, 2020), divulgada em junho de 2020 pelo IBGE, 6,9 milhões de pessoas realizaram trabalho voluntário sem receber remuneração em 2019 (IBGE, 2020). Além disso, para Junqueira (2010, p. 186), alguns trabalhadores comunitários após o cumprimento da pena continuam prestando trabalho voluntário por sentirem-se úteis e valorizados pela instituição.

Uma linha tênue traçada pela imposição judicial separa o trabalho comunitário do voluntário. Nesse sentido, Carnelutti (2015) coloca que se a pena fosse espontânea, voluntária e interesse da pessoa, ao invés de uma obrigação imposta ao indivíduo, seu caráter punitivo desapareceria. Assim, “[...] certas medidas impostas pela lei [...] tanto adquirem caráter de pena quanto não sejam queridas por quem as sofre. Se este as quer é, como se acostuma dizer, exercício de liberdade [...]" (CARNELUTTI, 2015. p. 52) e não punição.

\section{O TRABALHO COMUNITÁRIO COMO PREVENÇÃO ESPECIAL DA PENA}

A função de prevenção geral especial negativa da pena consiste na neutralização do réu condenado tirando-lhe “ [...] o poder físico de fazer o mal” (BENTHAM, 2002, p. 24). Ao inabilitá-lo, mesmo que temporariamente, a cometer outros crimes garante a segurança social da sociedade. Em matéria de eficiência a neutralização divide-se em neutralização total ou parcial. A única pena capaz de atingir a neutralização total é a de morte pela inativação absoluta de qualquer ação. "Tudo quanto se podia recear de um criminoso, seja pelo seu caráter arrebatado, seja pelo sonegado de seus procedimentos, fica desvanecido no mesmo instante" (BENTHAM, 2002, p. 169) que a vida é ceifada. Todas as demais penas, dentre essas a prestação de serviços à comunidade, pertencem a neutralização parcial.

Alguns meios físicos, químicos, eletrônicos e outros são utilizados para retirar ou restringir as condições necessárias a conduta delituosa, como as prisões por exemplo. 


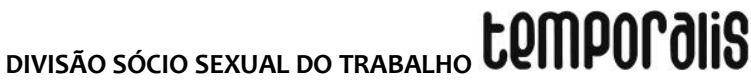

Dentro dessa concepção, se ninguém pode estar em dois lugares ao mesmo tempo, então o trabalhador comunitário, desde que estivesse prestando serviços à instituição, teria teoricamente restrito seu poder de cometer delitos em outro lugar por determinado tempo. Aquele lugar o confina, o contém, limita sua ação a determinado espaço no tempo, todavia nada impede que novos delitos aconteçam no próprio local de execução da pena ou em outro local de forma indireta. A neutralização artificial criada pela sua presença física na instituição pode ser rompida facilmente com o uso de tecnologias para organizar e ordenar delitos como acontece dentro dos presídios ou para praticar crimes virtuais pela internet.

Por outro lado, a função de prevenção especial positiva da pena, ao invés da neutralização, busca a correção do criminoso pela "educação" e "(re) socialização" com objetivo de prevenir a reincidência criminal. No século XIX, de acordo Hassemer (2006) três fatores impulsionaram as ideias de ressocialização na esfera jurídica. O desenvolvimento das ciências empíricas e humanas apoiadas na crença da racionalidade da observação e controle do mundo, por meio da intervenção técnica, serviram de alicerce para crença que seria possível influenciar e modificar os fenômenos vinculados ao crime e a conduta desviante atrás da intervenção técnica adequada. Outro fator, era a necessidade de legitimação do Estado moderno que precisava justificar seu poder punitivo. E por último, a instituição da pena de privação de liberdade torna necessário, inevitavelmente, uma teoria da ressocialização para justificar, não só a pena privativa de liberdade, mas também o tempo ocioso do condenado dentro das prisões. Para ressocializar e preencher esse tempo ocioso dentro das prisões o Estado, como mostra a história, sempre usou técnicas de adaptação sendo, geralmente, a oração, o trabalho e a socioterapia (HASSEMER, 2006, p. 9-10).

Na pena de prestação de serviços à comunidade, ao contrário da prisão, todo o tempo é consumido com o trabalho que media a relação entre o trabalhador comunitário e a instituição. O trabalho comunitário é utilizado como instrumento para "educar" e "corrigir" o trabalhador comunitário, para que não volte a cometer outros delitos. A função "educativa" e "corretiva" da pena de PSC não se vincula a uma visão dicotômica do trabalho na qual o trabalho comunitário intelectual (auxiliar administrativo por exemplo) seria "educativo", enquanto o trabalho comunitário manual (como por exemplo serviços gerais) não seria "educativo".

Também, não pode ser concebido como algo complementar e exterior ao trabalho comunitário. Sena (2012), ao imaginar, de forma equivocada, a função educativa na PSC como algo complementar ao trabalho comunitário crítica o fato das "[...] instituições recebedoras dos penalizados com a prestação de serviços quedam-se inertes no seu papel educativo, haja vista os depoimentos de quase total ausência de atividades educativas paralelas à execução da pena" (SENA, 2012, p. 71). O processo "educativo" da PSC não é uma coisa exterior ao trabalho comunitário, embora seja positivo atividades educacionais complementares, nem algo imanente da natureza desse trabalho.

Independentemente de ser material/imaterial ou ter atividades pedagógicos complementares, o trabalho comunitário possibilita o estabelecimento de relações

Temporalis, Brasília (DF), ano 20, n. 40, p. 233-249, jul./dez. 2020. | ISSN 2238-1856 


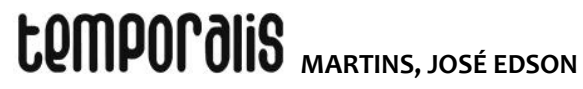

sociais, na medida em que os homens ao trabalhar estabelecem entre si relações sociais que correspondem, em última instância, ao modo de produção vigente. Tais interações sociais, mediadas pelo trabalho, juntamente com a linguagem criam condições favoráveis a " (re) educação" e a socialização, visto que "[...] todos os processos de socialização [primário ou secundário] se realizam numa interação face a face com outras pessoas" (BERGER; BERGER, 1977, p. 215). Deste modo, “[...] a prestação de serviços à comunidade, como possibilidade de educação, responsabilização e (re) inserção, concretiza-se nas múltiplas interações pelos sujeitos em contextos específicos [...]" (JUNQUEIRA, 2010, p. 92) de cumprimento da PSC. Tais interações levam os trabalhadores comunitários a experimentarem "[...] mudança de valores, formação de novos amigos, relações de colaboração, sentimento de respeito, tudo isso [...], demonstram o possível desenvolvimento de sentimento de solidariedade, para uma melhor convivência social" (SENA, 2012, p. 71).

Nesse processo "educativo" uma grande parte dos trabalhadores comunitários são trabalhadores assalariados. Diante disso, o trabalho comunitário poderia ser um mecanismo adequado para a "(re) educação" desses trabalhadores? A princípio o trabalho em uma fábrica, uma prisão e uma instituição sem fins lucrativos não se diferenciam muito e guardam semelhanças, como por exemplo: a divisão social do trabalho, a perda de autônima na organização do trabalho, etc., mas há diferenças. Mesmo que o trabalho em determina cargo ou profissão seja executado de forma idêntico ou semelhante em uma fábrica, prisão ou instituição sem fins lucrativos, como serviço de limpeza por exemplo, as condições sociais nas quais objetivam-se produzem distintas relações sociais mediadas pelo trabalho que, por sua vez, produz diferentes interações sociais, experiências de vida, conhecimentos profissionais, aprendizagens, valores e habilidades sociais.

Isso possibilita de forma indireta a formação e qualificação da mão de obra assalariada durante o cumprimento da PSC. E, também, incentiva a aprendizagem de valores e internalização de comportamentos ligados a uma "ética do trabalho", como por exemplo comprometimento com a instituição, assiduidade, cooperação, obediência a regras e hierarquias e outros. Nesse sentido, um trabalhador comunitário afirmou que "[ a PSC] profissionalmente me ensinou muito porque já sei como me comportar em um ambiente de trabalho [...]" (ENTREVISTADO apud JUNQUEIRA, 2010, p. 140). Tais habilidades e a introjeção de uma "ética do trabalho" poderão facilitar a "(re) inserção" do trabalhador comunitário no mercado de trabalho ou, em alguns casos, até conseguir um emprego na própria instituição que prestou serviços à comunidade.

Soma-se a tudo isso, um forte sentimento de utilidade social (JUNQUEIRA, 2010, p. 136) despertado no trabalhador comunitário, na proporção em que o trabalho comunitário é valorizado pela instituição sem fins lucrativos e reconhecido pela comunidade local. Para Bitencourt (2000), isso leva naturalmente o trabalhador comunitário a "[...] reflexão sobre seu ato ilícito, a sanção sofrida, o trabalho realizado, a aceitação pela comunidade e a escala de valores comumente aceita por ela. Tal reflexão facilita o propósito pessoal de ressocializar-se [...]" (BITENCOURT, 2000, p. 141) dentro do chamado "tratamento ressocializador mínimo". 


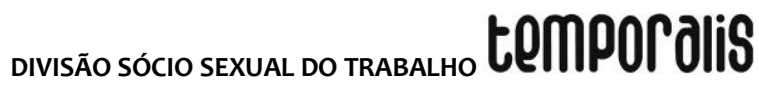

$\mathrm{Na}$ contemporaneidade, “[...] só se concebe o esforço ressocializador como uma faculdade que se oferece ao delinquente para que, de forma espontânea, ajude a si próprio a, no futuro, levar uma vida sem praticar crimes" (BITENCOURT, 2000, p. 18). Em um Estado Democrático de Direito o condenado "[...] tem o direito de escolher seus próprios conceitos, suas ideologias, suas escalas de valores” (BITENCOURT, 2000, p. 18). Nessa direção, nas palavras de Shecaria (1993):

O caráter educativo de serviços à comunidade, chamado de prevenção especial,
não tem o sentido de induzir alguém a 'melhorar' sua personalidade, mas
somente o de incutir a idéia de não repetir o crime [...]. Esta pena não quer exigir
que o condenado pense e aja como toda sociedade, nem ao menos como a
média das pessoas, mas pretende fazer com que o agente entenda que, mesmo
com diferenças entre as pessoas, ele deve submeter-se a um padrão ético
mínimo, que permita a convivência entre os homens, de forma pacífica
(SHECARIA, 1993, p. 59).

Na prática tal caráter educativo, “(re) socializador”, de certa forma, não é só uma faculdade passiva oferecida ao trabalhador comunitário. Ao contrário, é uma faculdade ativa que busca adaptar e ajustar o trabalhador comunitário à sociedade brasileira. Apesar dessa faculdade não se impor de forma despótica, estimula, induz, premeia o "bom" comportamento e reprova o "mal" comportamento tentando convencer o trabalhador comunitário a obedecer às normas sociais e jurídicas vigentes e, consequentemente, submeter-se, de certa forma, aos valores sociais, ideias, em fim a um padrão ético dominante ${ }^{11}$ contido em tais normas jurídicas.

Mas, “[...] o que é realmente um 'delinquente ressocializado?' Ele é 'saudável' (e o que é isto?), ele é 'leal à moral' ou ele é apenas 'leal ao direito' (e ele o é então externamente ou também internamente?)? [...]” (HASSEMER, 2006, p. 10). São perguntas difíceis de responder, contudo é possível deduzir que para Bitencourt (2002) e Shecaria (1993) um "delinquente ressocializado" seria aquele que não prática novos crimes. A não reincidência criminal sinalizaria uma determinada subordinação e obediência as normas jurídicas vigentes, mas não sinalizaria uma aceitação total à moral ou uma submissão total a um padrão ético dominante. Nessa concepção, por outro lado, toda reincidência seria uma prova contra a eficácia do trabalho comunitário como instrumento de prevenção especial positiva.

\section{CONCLUSÃO}

É inegável a centralidade do trabalho comunitário na organização da pena alternativa de prestação de serviços à comunidade, no entanto a utilização do trabalho comunitário para os fins de retribuição, prevenção geral e especial, combinados na teoria mista da pena, não produz os resultados esperados. O emprego do trabalho comunitário, como instrumento de retribuição penal, depende de condições externas ao trabalho. É a

\footnotetext{
11 "As idéias (Gedanken) da classe dominante são, em todas as épocas, as idéias dominantes, ou seja, a classe que é a força material dominante da sociedade é, ao mesmo tempo, sua força espiritual dominante" (MARX; ENGELS, 2006, p.78).
} 


\section{temporalis \\ MARTINS, JOSÉ EDSON}

característica de gratuidade do trabalho comunitário e não o próprio trabalho que provoca a aflição, a expiação e o sofrimento necessário para retribuição do "mal injusto" causado pelo crime.

O trabalho comunitário, no que diz respeito a prevenção geral, não produz, de forma significativa, na população os efeitos simbólicos de intimidação, coação psicológica e confiança na lei indispensáveis a inibição de delitos e prevenção de futuros crimes. A validade da lei violada é reafirmada pelo trabalho comunitário como qualquer outra pena reafirma, mas não demonstra potencial expressivo para reforçar a confiança na norma jurídica. Soma a isso os fortes indícios de que a tentativa de intimidação e ameaça penal, por meio do trabalho comunitário, produz efeitos simbólicos e psicológicos bastante inexpressivo sob os trabalhadores típicos, desempregados e desalentados, contudo os não trabalhadores, talvez, sejam mais suscetíveis a tais efeitos.

Na prevenção especial os resultados de neutralização e inabilitação a prática delituosa utilizando o trabalho comunitário são limitados e parciais. As relações sociais, por outro lado, mediadas pelo trabalho comunitário, criam condições favoráveis a ação pedagógica e a socialização que, consequentemente, induzem e incentivam a subordinação as normas jurídicas vigentes, bem como a internalização de padrões de valores e comportamentos valorizados e legitimados socialmente. Contudo, a reincidência criminal de egressos da pena alternativa de PSC sugere que o caráter educativo do trabalho comunitário, também, apresenta resultados limitados e parciais.

\section{REFERÊNCIAS}

BARRETO, F. C. O. Dez anos da política nacional de penas e medidas alternativas. Brasília (DF): Ministério da Justiça, 2010. Disponível em:

http://antigo.depen.gov.br/DEPEN/dirpp/cgap/pesquisas/diagnostico10anospoliticanacion alpenasmedi.pdf. Acesso em: 17 ago. 2019

BECCARIA, C. Dos delitos e das penas. Tradução de Paulo M. Oliveira. Rio de Janeiro: Edipro, 2010.

BENTHAM, J. Teoria das penas legais. Campinas: Bookseller, 2002.

BERGER, P. L.; BERGER, B. Socialização: como ser um membro da sociedade. In: FORACCHI, M. M.; MARTINS, J. S. (org.). Sociologia e sociedade: leituras e introdução à sociologia. Rio de Janeiro: S.A., 1977, p. 200-214.

BICUDO, T. V. Por que punir?: teoria geral da pena. São Paulo: Saraiva, 2010.

BITENCOURT, C. R. Novas penas alternativas: análise político-criminal das alterações da lei n.9.714/98. 2. ed. São Paulo: Saraiva, 2000.

BÔAS, B.V. IBGE: antes da pandemia, trabalho voluntário estava em tendência de baixa. Jornal Valor Econômico, Rio de Janeiro, 4 jul. 2020. Disponível em: 


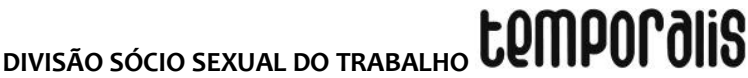

https://valor.globo.com/brasil/noticia/2020/06/04/ibge-antes-da-pandemia-trabalhovoluntario-estava-em-tendencia-de-baixa.ghtml. Acesso em: 4 jul. 2020.

BRASIL. Decreto-lei 2.848 de 7 de dezembro de 1940. Código Penal. Diário Oficial da União, Brasília, DF, 31 dez. 1940. Disponível em:

http://www.planalto.gov.br/ccivil_03/decreto-lei/Del2848compilado.htm. Acesso em: 17 ago. 2019.

BRASIL. Lei $n^{\circ} 9714$, de 25 de novembro de 1998. Altera dispositivos do Decreto-lei $n^{\circ}$ 2848, de 7 de dezembro de 1940 - Código Penal. Diário Oficial da União, Brasília (DF), 26 nov. 1998. Disponível em: http://twixar.me/Q4F1. Acesso em: 17 ago. 2019.

BRASIL. Lei n 7.209 , de 11 julho de 1984 . Altera dispositivos do Decreto-lei $n^{\circ} 2.848$, de 7 de dezembro de 1940 - Código Penal. Diário Oficial da União, Brasília (DF), 13 de jul. 1984. Disponível em: http://twixar.me/24F1. Acesso em: 17 ago. 2019.

BRASIL. Código criminal do Império do Brasil, de 16 de dezembro de 1830. Disponível em: http://twixar.me/3IF1. Acesso em: 17 ago. 2019.

CACICEDO, P. L. Pena e funcionalismo sistêmico: uma análise crítica da prevenção geral positiva. 2014. Dissertação (Mestrado em Direito) - Faculdade de Direito, Universidade de São Paulo, São Paulo, 2014. Disponível em: http://twixar.me/dr4K. Acesso em: 2 jan. 2019.

CARNELUTTI, Francesco. O problema da pena. Tradução Ricardo Pérez Banega. São Paulo: Pillares, 2015.

FELIPETO, R. Prestação de serviços à comunidade. Revista Brasileira de Ciências Criminais, São Paulo, v.7, p. 140-152, jul./set. 1994.

GIL, A. C. Métodos e técnicas de pesquisa social. 6. ed. São Paulo: Atlas, 2008.

HASSEMER, W. Ressocialização e estado de direito. Revista de Estudos Criminais, Ano VI, n. 21, p. 9-13, jan./mar. 2006.

IBGE. PNAD Contínua: taxa de desocupação é de 12,9\% e taxa de subutilização é de 27,5\% no trimestre encerrado em maio de 2020. [S. I.]: IBGE, 2020. Disponível em: https://cutt.ly/coZsnzO. Acesso em: 06 jul. 2020

ILANUD BRASIL. Levantamento nacional sobre execução de penas alternativas: relatório final de pesquisa. [S. I.]: ILANUD Brasil, 2006. Disponível em:

http://www.institutoelo.org.br/site/files/arquivos/ofd18d6254539298f4103bea76fe4ego.p df. Acesso em: 14 jan. 2019.

JUNQUEIRA, M. R. Prestação de serviços à comunidade: Impacto e (In) Visibilidade no Cumprimento da Pena/Medida Alternativa. Dissertação. 2010. 266f. Dissertação 


\section{temporalis}

MARTINS, JOSÉ EDSON

(Mestrado em Educação) - Faculdade de Educação, Universidade Federal do Rio Grande do Sul, Porto Alegre, 2010. Disponível em: http://twixar.me/8r4K. Acesso em: 08 jan. 2019.

LIMA, A. S. A validade da norma jurídica na doutrina de Kelsen. Revista Pensar, Fortaleza, v. 2, n. 2, p. 89-99, ago. 1993. Disponível em: https://bit.ly/2l1u8tf. Acesso em: 08 jan. 2019.

MARTINS, J. E. A Centralidade do Trabalho na Medida Socioeducativa de Prestação de Serviços à Comunidade. Revista Barbarói, Santa Cruz do Sul, n. 48, p.86-105, 2016. Disponível em: https://bit.ly/2/2GPEf . Acesso em: 08 jan. 2019.

MARX, K. Grundrisse: manuscritos econômicos de 1857-1858: esboços da crítica da economia política. Tradução de Mario Duayer; Nélio Schneider. São Paulo: Boitempo; Rio de Janeiro: UFRJ, 2011.

MARX, K. Contribuição à crítica da economia política. Tradução de Florestan Fernandes. 2. ed. São Paulo: Expressão Popular, 2008a.

MARX, K. Manuscritos econômicos-filosóficos. Tradução de Jesus Ranieri. São Paulo: Boitempo, 2008b.

MARX, K; ENGLES, F. Ideológica Alemã: Fuerbach - a contraposição entre as cosmovisões materialista e idealista. Tradução de Martin Claret. São Paulo: Cortez, 2006. (Coleção obra-prima de cada autor).

OFFE, C. Trabalho: a categoria-chave da sociologia?. RBCS: Revista Brasileira de Ciências Sociais, São Paulo, USP, v.4, n.10, p.6-20, 1989.

OLIVEIRA, C. M. Os benefícios da prestação de serviços à comunidade como alternativa a pena privativa de liberdade: experiência da comarca de Duque de Caxias. 2011. 105f. Dissertação (Mestrado em Serviço social) - Pontifícia Universidade Católica do Rio de Janeiro, Rio de Janeiro, 2011. Disponível em: http://twixar.me/vr4K. Acesso em: 08 jan. 2019 .

PRADO, L. R. Teoria dos fins da pena: breves reflexões. Ciências Penais, vol. o, p. 143, jan. 2004. Disponível em: http://twixar.me/PCD1. Acesso em: 08 jan. 2019.

SANTOS, J. C. Teoria da pena. In: SANTOS, J. C. Direito penal: parte geral. 3. Ed. Curitiba: ICP, Lumen Juris, 2008. p. 457-497.

SENA, G. A. A Potencialidade educativa da pena de prestação de serviços à comunidade. 2012. 95f. Dissertação (Mestrado Profissional em Poder Judiciário) - Escola de Direito do Rio de Janeiro, Rio de Janeiro, 2012. Disponível em: https://bit.ly/2 YU7VCv. Acesso em: 08 jan. 2019.

SPC BRASIL. 29\% dos trabalhadores relatam temor alto ou médio de serem demitidos, revela indicador da CNDL/SPC Brasil. SPC Brasil, Índices Econômicos, 2018. Disponível em: https://bit.ly/2KcOYrH. Acesso em: 20 mar. 2019. 
SHECARIA, S. S. Prestação de serviços à comunidade: alternativa à pena privativa de liberdade. São Paulo: Saraiva, 1993. 